\title{
Review Article \\ Therapeutic Potential of Inorganic Nanoparticles for the Delivery of Monoclonal Antibodies
}

\author{
Christopher T. Turner, ${ }^{1}$ Steven J. P. McInnes, ${ }^{2}$ Nicolas H. Voelcker, ${ }^{2}$ and Allison J. Cowin ${ }^{1}$ \\ ${ }^{1}$ Regenerative Medicine, Mawson Institute, University of South Australia, Adelaide, SA 5001, Australia \\ ${ }^{2}$ ARC Centre of Excellence in Convergent Bio-Nano Science and Technology, Mawson Institute, University of South Australia, \\ Adelaide, SA 5001, Australia
}

Correspondence should be addressed to Allison J. Cowin; allison.cowin@unisa.edu.au

Received 3 November 2014; Accepted 25 November 2014

Academic Editor: Haifeng Chen

Copyright (C) 2015 Christopher T. Turner et al. This is an open access article distributed under the Creative Commons Attribution License, which permits unrestricted use, distribution, and reproduction in any medium, provided the original work is properly cited.

\begin{abstract}
Monoclonal antibodies (mAbs), available for a range of diseases, including tumours, leukemia, and multiple sclerosis, are emerging as the fastest growing area of therapeutic drug development. The greatest advantage of therapeutic mAbs is their ability to bind with a high degree of specificity to target proteins involved in disease pathophysiology. In response, effector functions are triggered and these ameliorate the disease cascade. As an alternative to this reliance on effector functions, drugs can be conjugated to $\mathrm{mAbs}$. The ability to target compounds to the site of pathology minimises the nonspecific side effects associated with systemic administration. In both instances, optimising the delivery, absorption, and distribution of the mAbs, whilst minimising potential side effects, remain the key hurdles to improved clinical outcomes. Novel delivery strategies are being investigated with more vigour in recent years, and nanoparticles are being identified as suitable vehicles. In conjunction with permitting a controlled release profile, nanoparticles protect the drug from degradation, reducing both the dose and frequency of administration. Moreover, these particles shield the patient from the immune complications associated with high dose $\mathrm{mAb}$ infusions or drug cytotoxicity. This review outlines recent advances in nanoparticle technology and how they may be of benefit as therapeutic mAb delivery/targeting vehicles.
\end{abstract}

\section{Therapeutic mAbs}

Therapeutic monoclonal antibodies (mAbs) are monospecific antibodies designed to target proteins involved in the pathophysiology of disease. By binding with high specificity to these target proteins, the development/progression of the disease is ameliorated, leading to improved clinical outcomes. Specificity is probably the greatest advantage of $\mathrm{mAb}$ therapy as the production of antibodies to specific antigenic domains provides a mechanism to directly target the site/s of pathology.

Therapeutic $\mathrm{mAbs}$ are clinically approved to treat a range of diseases; solid tumors, including colorectal carcinoma and squamous cell carcinoma of head/neck; haematological cancer, including chronic lymphocytic leukemia; inflammatory diseases, such as rheumatoid arthritis, multiple sclerosis, psoriasis, asthma, and transplant rejection; and other disorders including virus infection and wet age-related macular degeneration. There are $>30 \mathrm{mAb}$ therapies clinically approved worldwide, with current global sales at approximately $\$ 40$ billion per annum. Hundreds more therapeutic mAbs are being developed, undergoing preclinical or clinical trials to treat other diseases or to improve existing $\mathrm{mAb}$ treatment regimens.

\section{Structure}

The main type of therapeutic $\mathrm{mAb}$ is IgG, approximately $150 \mathrm{kDa}$ sized Y-shaped protein structures comprised of two heavy chains linked by disulphide bridges to two light chains (Figure 1(a)). IgG antibodies contain two identical antigen binding sites (Fab), each containing complementarity determining regions (CDRs), which are variable in sequence. IgG antibodies also contain a conserved $\mathrm{Fc}$ domain which 


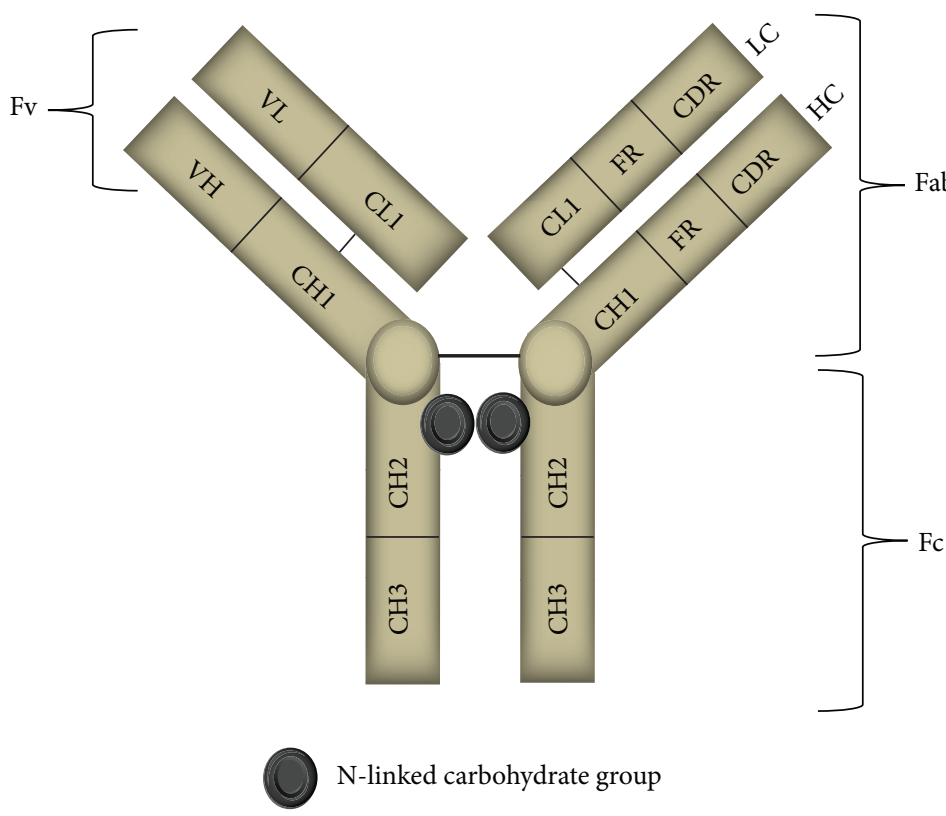

(a)
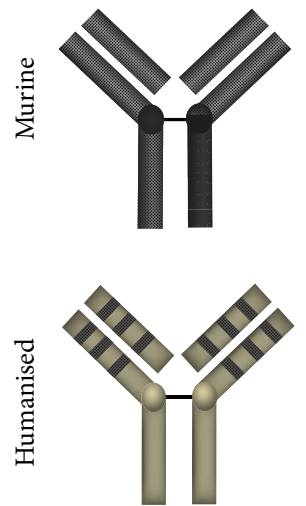

Murine sequence Human sequence
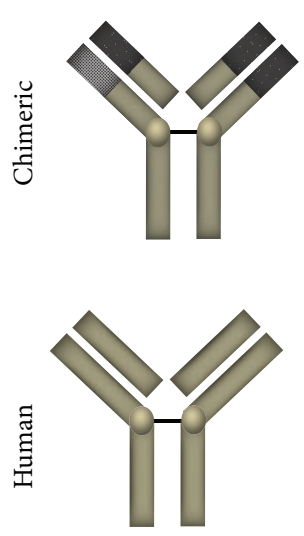

(b)

Figure 1: The structural elements of IgG. (a) The two identical Fv (variable fragment) domains bind to the target protein with high specificity. The Fc (constant fragment) domain binds to the Fc receptor of immune cells, triggering effector functions, including CDC and ADCC. LC = light chain, $\mathrm{HC}=$ heavy chain, $\mathrm{CDR}=$ complementarity determining region, $\mathrm{CL}=$ light chain constant region, $\mathrm{CH}=$ heavy chain constant region, $\mathrm{FR}$ = framework, $\mathrm{VL}$ = light chain variable region, $\mathrm{VH}=$ heavy chain variable region. (b) IgG murine sequence can be replaced with human sequence to reduce immunogenicity. Commercially available mAbs include chimeric, humanised, and human IgG. Adapted from Maynard and Georgiou, 2000 [1].

plays a role in modulating immune cell activity, including complement activation [2], and regulating serum half-life [3].

Using recombinant technology, alternative mAb structures have been developed that provide specific therapeutic benefits. The smallest functional fragments of antibodies that can bind to the antigen (the variable regions $(\mathrm{Fv})$ of both light and heavy chains) can be joined together with a flexible peptide linker to produce a single chain variable fragment ( $\mathrm{scFv}$; Figure 2) [1]. The advantage of these antibody fragments as a therapeutic $\mathrm{mAb}$ is a reduction in size (approximately $27 \mathrm{kDa}$ ), thereby allowing greater tissue penetration, which is especially important for the treatment of solid tumors. Other advantages include lower cost, faster manufacturing, and the ability to better control avidity, affinity, and pharmacokinetics [4].

Recombinant techniques have allowed antibody fragments, including $\mathrm{scFv}$ and single domains, to be multimerised to produce antibodies with different sizes, valencies, and effector functions. Two main types of antibody have been produced; multivalent antibodies that imitate the structure of IgG are classified as orthodox [5]. These antibodies include $(\mathrm{Fab})_{2} / \mathrm{sc}\left(\mathrm{Fab}^{\prime}\right)_{2}$, tribodies, and minibodies (Figure 2). NonIgG like structures are called heterodox and include diabodies, triabodies, and tetrabodies. Other multivalent antibodies include $\mathrm{scFv}_{2}$ /BITEs, streptabodies, and tandem diabodies.

Therapeutic $\mathrm{mAbs}$ can be tagged with toxins [6] or radioactive material [7], allowing the targeted traffic of cytotoxic compounds to cancer cells. mAbs have also been conjugated to anticancer compounds, including Brentuximab (antiCD30), which is conjugated to monomethyl auristatin E, a potent inhibitor of microtubule polymerisation. Tositumomab (anti-CD20), conjugated to iodine-131, was developed for the treatment of refractory, or relapsed, follicular lymphoma patients [7]. This antibody strategy provides a more directed approach to destroy cancer cells than existing methods, including chemotherapy. The only other clinically approved therapeutic compound that contains a cytotoxic payload is Ibritumomab (anti-CD20; non-Hodgkin's lymphoma), which is also conjugated to iodine-131. These drugconjugated mAbs are advantageous over other mAbs as cytotoxic compounds typically have a more pronounced biological effect than the reliance on antibody effector functions alone, although the side effects are also more pronounced. For example, Gemtuzumab, an anti-CD33 antibody conjugated to ozogamicin, was removed from the market in 2010 due to increased patient mortality compared to other existing treatments.

\section{Mechanism of Action}

Following the binding of a $\mathrm{mAb}$ to the target, effector functions are triggered. There are four main types of effector functions; neutralisation, antibody-dependent cellular cytotoxicity (ADCC), opsonisation, and complement activation. Neutralisation occurs when the $\mathrm{mAb}$ binds to the target 

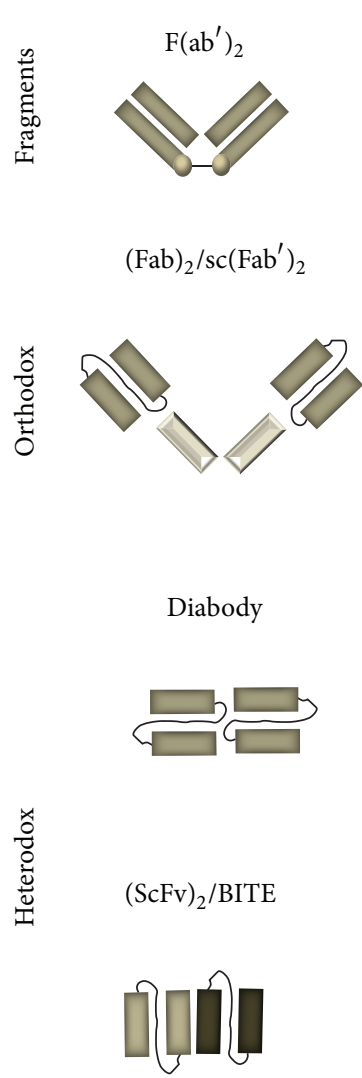
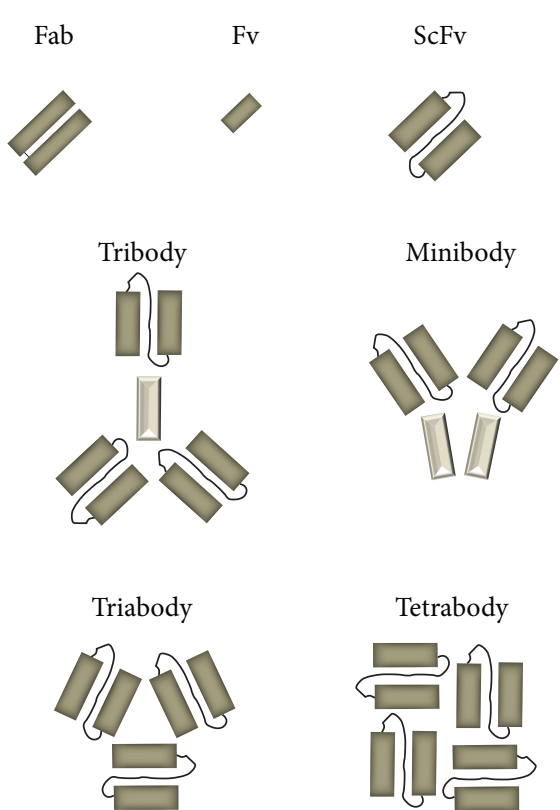

Streptabody

Tandem diabody

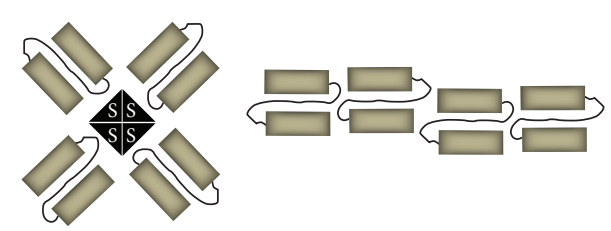

FIGURE 2: Non-IgG mAb structures. Recombinant technology allows the manufacture of novel mAb structures that allow altered affinity, avidity, tissue penetration, and tissue half-life. Antibody structures include fragments, orthodox (IgG-like structures), and heterodox (nonIgG-like structures). Some antibodies are developed to contain multiple binding sites, allowing improved avidity (i.e., tandem diabody), and different binding sites (i.e., $(\mathrm{ScFv})_{2} / \mathrm{BITE}$ which can bind to two targets). $\mathrm{ScFv}=$ single chain variable fragment. BITE $=$ bi-specific T-cell engager.

protein in a surface location that prevents other proteinprotein interactions, essentially neutralising its function. In one study, the treatment of porcine excisional wounds with a $\mathrm{mAb}$ that neutralizes Flightless I, a cytoskeletal protein and negative regulator of wound healing, resulted in accelerated reepithelialisation and improved the macroscopic appearance of early scars [8].

ADCC and opsonisation induce antibody-mediated cytotoxicity and are valuable for the treatment of both hematological cancer and solid tumors. Both ADCC and opsonisation are triggered when the $\mathrm{Fc}$ domain of the $\mathrm{mAb}$ is targeted to the Fc receptor on the surface of immune cells. The binding of the mAbs CDR to the target protein (i.e., a cell surface protein elevated in cancer cells) along with the Fc domain recruitment of the immune cell allows the immune cell and target cell to be brought into close proximity, triggering chemokine, cytokine release, and targeted cell death. The effector cells that may mediate ADCC include NK cells, monocytes, macrophages, and neutrophils [9]. Rituximab, which targets the CD20 antigen on the surface of both malignant and normal B lymphocytes, has improved the outcome of patients with chronic lymphocytic leukemia and non-Hodgkin lymphoma and has been reported to predominantly function by the induction of ADCC [10].
Complement dependent cytotoxicity (CDC) can also be mediated through the Fc domain and is another method of inducing antibody-mediated cell death. CDC is dependent on the interaction between the $\mathrm{mAb}$ and soluble blood proteins that constitute the complement system [11]. Complement activation is initiated when the mAb, already attached to the surface of the target cell, binds to the soluble serum protein, $\mathrm{Clq}$. The activation of enzymatic activity in Clr follows Clq binding, triggering the complement cascade and subsequent cell death. Multiple IgG antibodies are required to be bound to the target cell for complement cascade initiation. ADCC, opsonisation, and CDC all appear to contribute together to varying degrees in the cell death observed in response to $\mathrm{mAb}$ treatment, due in part to the antibody isotype [12].

\section{Administration Route, Absorption, and Distribution}

Parenteral delivery, intravenous injection in particular, retains $100 \%$ bioavailability and is therefore the most common route of administration for clinically approved therapeutic mAbs $[3,13]$. Once in circulation, the mAbs diffuse into the peripheral tissue allowing binding to the target 
antigen. A number of mAbs are also administered subcutaneously, including Adalimumab (rheumatoid arthritis) and Efalizumab (plaque psoriasis), with absorption facilitated by the lymphatic system. This is associated with a reduction in bioavailability but is preferred due to an ability to increase the dose and the convenience of administration $[1,14]$. The reduction in bioavailability is predicted to be caused by the proteolytic degradation of the $\mathrm{mAb}$ in either the interstitial fluid or lymphatic system $[4,15]$. Other less common routes of administration are clinically approved, including intramuscular (used for respiratory syncytial virus infection), which also relies on absorption by the lymphatic system, and intraperitoneal (used for malignant ascites). Some mAbs are applied directly to the site of pathology, with Ranibizumab administered intravitreally to treat macular degeneration. In animal studies, dermal wounds and blisters have been treated topically (cream) and intradermally (injected) with an anti-Flightless $\mathrm{mAb}[5,8,16]$. Enteral delivery has not been adopted as a delivery route due to rapid $\mathrm{mAb}$ degradation upon exposure to the gastrointestinal tract $[6,13]$.

\section{Current Limitations of Therapeutic mAbs}

Despite the recent advances in mAb therapeutics, there are still limitations preventing effective patient treatment. One major limitation is the cost of treatment, which is elevated due to the cost of drug manufacture and the high dose required for efficacy in a number of diseases. To produce mAbs, the eukaryotic cells which secrete the mAb need to be maintained in culture. Extensive purification steps are also required to produce $\mathrm{mAb}$ under good manufacturing practice conditions $[7,17]$.

The high dose of $\mathrm{mAb}$ required per administration results from a combination of factors associated with pharmacodynamics and pharmacokinetics. mAbs have been shown to be retained in circulation rather than targeted to the site of pathology. IgG, which is larger than the renal clearance threshold, can have a biological half-life of up to 21 days $[7,18]$. Contributing to this long half-life in circulation is IgGs ability to bind the neonatal Fc receptor on the surface of a number of cell types, including immune cells and the vascular endothelium $[8,19]$. The mAb is internalized into the endosome-lysosome network of these cells, before being exocytosed back into the serum at a later date. The process of convection, which is the engulfment of antibody in the bloodstream, has also been reported to retain the $\mathrm{mAb}$ in circulation $[9,15]$.

The high dose of $\mathrm{mAb}$ required for therapy is also due to the limited ability of $\mathrm{mAb}$ to penetrate the target tissue, including solid tumors and the extracellular matrix, leading to an overall low level of tissue distribution. This is caused by the relatively large size and hydrophilic nature of the antibody $[10,15]$. Tumors in particular, where the blood supply is viscous and there is high interstitial fluid pressure, are difficult to penetrate $[11,17]$. This has been overcome to some extent by the use of antibody fragments, including scFv [12, 20], which at approximately $27 \mathrm{kDa}$, are 5 -fold smaller than IgG. The effectiveness of these fragments in cancer treatment is limited by the absence of the Fc domain, preventing antibodymediated cytotoxicity, but to compensate, the fragments can be conjugated to anti-cancer drugs [21]. Another limitation of antibody fragments as a therapeutic option is the relatively short half-life, with Fab and scFv reported to have biological half-lives of less than one day [17]. These fragments are smaller than the renal clearance threshold of $70 \mathrm{kDa}$ and are therefore quickly removed from circulation.

Another limitation of mAb therapy is the binding site barrier effect [17]. mAbs typically bind with high affinity to the target once administered, resulting in the $\mathrm{mAb}$ being immediately "mopped up" and preventing further penetration into the site of pathology [22]. This has been reported in the treatment of solid tumors, showing suboptimal efficacy when treated with high affinity mAbs [23]. To some extent, this has been alleviated by the development of mAbs that bind with lower affinity, but this can also reduce the total amount of $\mathrm{mAb}$ binding.

Hypersensitivity reactions are a common side effect of $\mathrm{mAb}$ therapy, in part due to the high dose of mAb administered, and often lead to therapy discontinuation [24]. The first therapeutic mAb, Muromonab (OKT3), a murine derived IgG clinically approved by the FDA in 1986 to treat transplant rejection, showed a $94 \%$ reversal in rejections, significantly better than the conventional steroid-treatment group, and an improved one-year graft survival [25]. However, fever, chills, intestinal complications, convulsions, and viral infections were identified [26]. The development of neutralizing antimouse antibody responses was also observed [27]. To avoid these complications, next generation chimerized, humanised, and completely human antibodies were developed that had reduced mouse protein sequence (Figure 1(b)). As an example, the humanised mAb, Ustekinumab, developed for psoriasis treatment, has been reported to have a reduced therapy discontinuation rate due to adverse effects than equivalent patients treated with a chimeric mAb (Infliximab) [24]. Deimmunisation, an alternative to humanization, has been used to decrease immunogenicity [28]. In one study, the replacement of 17 mouse residues with comparable human residues resulted in an antibody with the same specificity and affinity but demonstrated reduced immunogenicity [29]. Together, structural adaptations of IgG have allowed a reduction, but not complete removal, in the immune mediated complications associated with $\mathrm{mAb}$ therapies.

Side effects are also associated with the administration of drug conjugated mAbs. These toxic drugs can cause nonspecific cell death on route to the site of administration, whilst the $\mathrm{mAb}$ is retained in circulation or at the site of pathology. This can be somewhat avoided by using mAbs with shorter half-lives, although this can reduce the efficacy of treatment. A variety of new drugs as well as alternative methods to conjugate the drug to the $\mathrm{mAb}$ are currently being investigated to improve the safety and efficacy of these drug conjugated mAbs [30].

Together, there are a number of limitations preventing optimal patient treatment with therapeutic mAbs, necessitating the development of alternative methods to deliver these drugs to the site of pathology. Recently, nanoparticle systems have been investigated for the therapeutic delivery of drugs. 
TABLE 1: mAb combined with nanoparticles for a therapeutic application.

\begin{tabular}{|c|c|c|c|c|c|}
\hline Particle type & $\mathrm{mAb}$ & $\begin{array}{l}\text { Secondary } \\
\text { Payload }\end{array}$ & Mechanism & Disease & Literature studies \\
\hline \multirow{4}{*}{$\begin{array}{l}\text { Mesoporous } \\
\text { silica }\end{array}$} & $\alpha$-CTLA 4,8 & - & $\mathrm{mAb}$ effector functions & Melanoma & Lei et al., 2010 [31] \\
\hline & $\alpha$-Mesothelin & DOX & Drug cytotoxicity & Mesothelioma & Macura et al., 2013 [32] \\
\hline & $\alpha$-EGFR & Pyrrolidine-2 & Drug cytotoxicity & Lung cancer & Sundarraj et al., 2014 [33] \\
\hline & TRC105 & $\mathrm{DOX} /{ }^{64} \mathrm{Cu}$ & Drug cytotoxicity & Tumors & $\begin{array}{l}\text { Chen et al., } 2013 \text { and } \\
\quad 2014[34,35]\end{array}$ \\
\hline \multirow{5}{*}{ Porous Silicon } & Bevacizumab & - & Predicted for $\mathrm{mAb}$ effector functions & Cancer & Andrew et al., 2010 [36] \\
\hline & $\alpha-\operatorname{MLR} 2$ & Camptothecin & Drug cytotoxicity & Neuroblastoma & Secret et al., 2013 [37] \\
\hline & $\underset{(\alpha-\operatorname{CCL} 24)}{\mathrm{mAb} 528}$ & Camptothecin & Drug cytotoxicity & Glioblastoma & Secret et al., 2013 [37] \\
\hline & $\begin{array}{l}\text { Rituximab } \\
(\alpha-\mathrm{CD} 20)\end{array}$ & Camptothecin & Drug cytotoxicity & B Lymphoma & Secret et al., 2013 [37] \\
\hline & $\begin{array}{c}\text { FGK45 } \\
(\alpha-C D 20)\end{array}$ & - & Activate B cells & $\begin{array}{l}\text { Autoimmune } \\
\text { disease }\end{array}$ & Gu et al., 2012 [38] \\
\hline \multirow{2}{*}{ Gold } & $\begin{array}{l}\text { Tocilizumab } \\
\quad(\alpha \text {-IL- } 6)\end{array}$ & - & $\mathrm{mAb}$ effector functions & $\begin{array}{l}\text { Rheumatoid } \\
\text { arthritis }\end{array}$ & Lee et al., 2014 [39] \\
\hline & $\begin{array}{l}\text { Rituximab } \\
(\alpha-\mathrm{CD} 20)\end{array}$ & - & $\begin{array}{c}\text { Photothermal ablation and } \mathrm{mAb} \\
\text { effector functions }\end{array}$ & Lymphoma & Bisker et al., 2012 [40] \\
\hline \multirow{2}{*}{ Gold Nanorods } & $\alpha$-ICAM-1 & ${ }^{125} \mathrm{I}$ & Predicted for $\mathrm{mAb}$ effector functions & $\begin{array}{l}\text { Rheumatoid } \\
\text { arthritis }\end{array}$ & Shao et al., 2011 [41] \\
\hline & $\alpha$-EGFR & - & Infrared light induced cytotoxicity & Bladder cancer & Cho et al., 2014 [42] \\
\hline MFNP & $\alpha$-HER2 & - & Photothermal ablation & Breast cancer & Shen et al., 2014 [43] \\
\hline Nanographene & $\begin{array}{c}\mathrm{TRC105} \\
(\alpha-\mathrm{CD} 105) \\
\end{array}$ & - & $\begin{array}{l}\text { Predicted for photothermal ablation } \\
\text { and mAb effector functions }\end{array}$ & Breast cancer & Hong et al., 2012 [44] \\
\hline SPION & $\alpha$-neu receptor & - & Predicted for $\mathrm{mAb}$ effector functions & Breast cancer & Kievit et al., 2012 [45] \\
\hline
\end{tabular}

MFNP = multifunctional nanoparticles. SPION = superparamagnetic iron oxide nanoparticle. ICAM1 $=$ intercellular adhesion molecule 1. DOX $=$ doxorubicin.

Nanoparticles offer many advantages, including protection of the drug from degradation during delivery to the site of pathology, controlling the rate of drug release over time and shielding the patient from cytotoxic drugs until they reach the site of pathology. Nanoparticles can be divided into two main types: polymeric, including pegylated liposomal vehicle and albumin vehicles, and inorganic, including porous silicon and gold nanotubes. Polymeric nanoparticles have been reviewed elsewhere $[13,46]$ and some highly relevant examples of cutting edge polymeric systems are also available [47-53] and so will not be discussed further. However, it is important to note that two of these polymeric preparations, Doxil (PEGylated liposomal vehicle) and Abraxane (albumin vehicle), have already been FDA approved for cancer therapy [54, 55]. In contrast, the development of inorganic nanoparticles for $\mathrm{mAb}$ delivery is still in its infancy but shows great promise as a therapeutic. This review will focus on recent developments in the use of inorganic nanoparticles as potential therapeutic $\mathrm{mAb}$ delivery vehicles.

\section{Inorganic Nanoparticles for Drug Delivery}

Inorganic nanoparticles are being manufactured for a wide variety of purposes, including many promising biomedical applications. There are now a wide variety of nanostructures being tailored for specific drug delivery applications, including (1) the delivery of therapeutic mAbs or (2) the use of mAbs for the targeted delivery of therapeutic payloads (Table 1). The most common materials include mesoporous silica nanoparticles [56], porous silicon [57, 58], silicon nanowires [59], carbon nanotubes [60], gold nanoparticles [61], and calcium phosphate [62] (Figure 3). Each of these nanoparticles provides unique properties that can be tailored to specific drug delivery or targeting applications. This review will discuss these advantages as well as summarizing the current literature showing the potential benefit of combining $\mathrm{mAbs}$ with inorganic nanoparticles.

6.1. Advantages of Inorganic Nanoparticle Delivery Systems for $m A b$ Delivery and Targeting. The use of inorganic nanoparticles for applications in $\mathrm{mAb}$ delivery presents a wide array of advantages, with each different material including some or all of the following.

(1) Ease of functionality with a range of surface and conjugation chemistries which can be carefully selected based upon the base material used, allowing attachment of various $\mathrm{mAb}$ structures and cytotoxic drugs. 

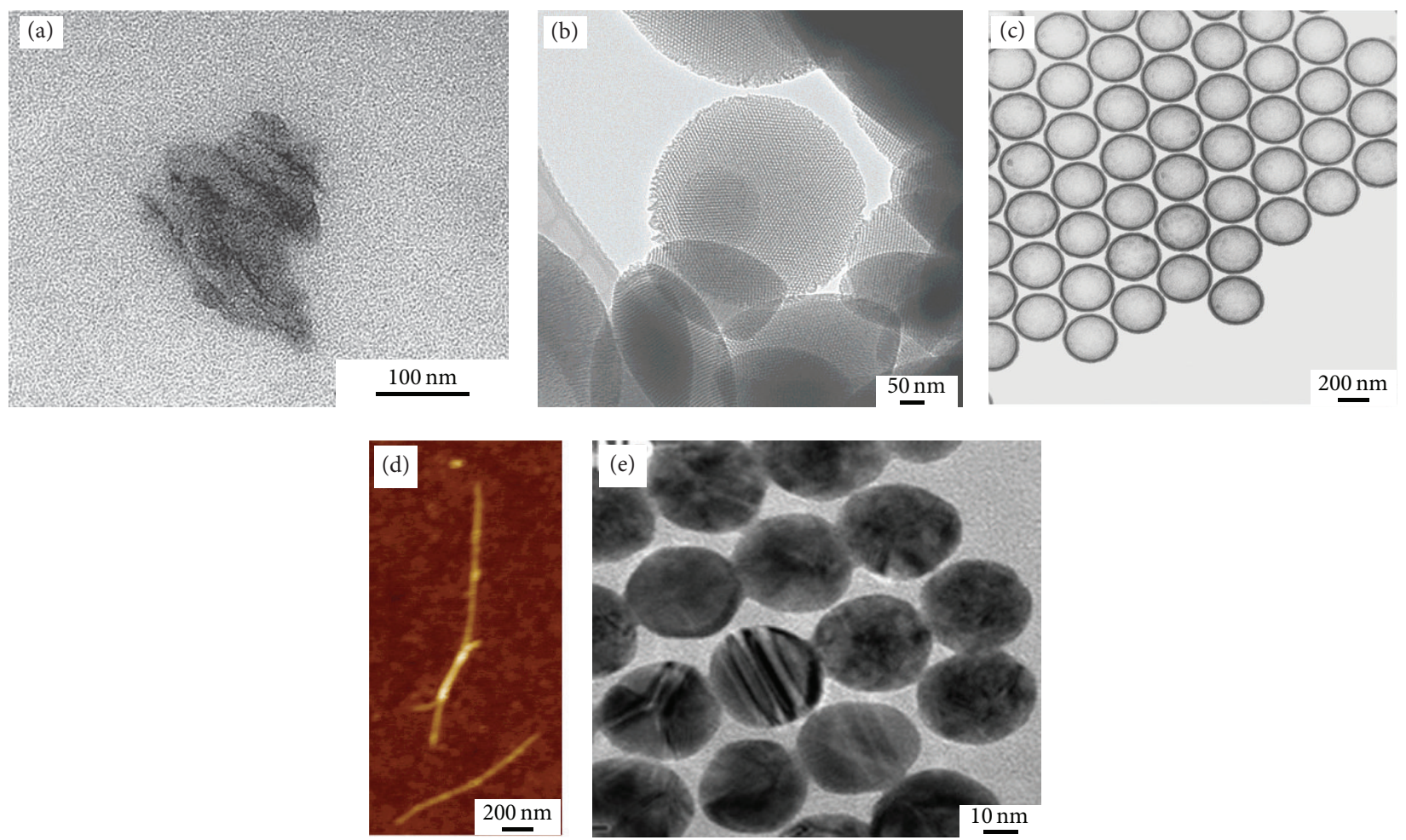

FIgURE 3: Typical inorganic nanomaterials under investigation for various biomedical applications such as the localized delivery of drugs. (a) Porous silicon nanoparticles from Secret et al. 2013 [37], (b) mesoporous silica nanoparticles from Slowing et al. 2007 [63], (c) hollow silica nanoparticles from Deng et al. 2011 [64], (d) single walled CNTs from Kam and Dai 2005 [65], and (e) gold nanoparticles from Tiwari et al. 2014 [66].

(2) High payload loadings, which are determined by the porosity and pore size of the material, the payload properties, and the surface chemistry chosen.

(3) Tunable degradation rates, which are controlled by the chosen surface chemistry and the base material properties, and controlled release kinetics based on the material/payload interaction and/or capping mechanism selected.

(4) Payload protection, controlled by the ability of the porous material to house the payload inside an inaccessible porous network until release, hence improving the in vivo half-life.

(5) Localized and targeted delivery, magnetically or antibody-targeted nanoparticles to specific tissue/disease sites.

(6) Enhanced penetration into tissue and certain nanomaterials can be designed so that they can effectively transverse specific tissue barriers.

(7) Exploitation of the enhanced permeation and retention effect $[67,68]$, where certain sized nanoparticles naturally accumulate in tumor tissue due to the lack of a lymphatic system, and hence, the ability to filter particles.
(8) The ability of nanoparticle preparations to traffic mAbs into the cytosol or other cellular compartments, significantly broadening the number of antigens the $\mathrm{mAb}$ could be designed to target, currently a major limiting factor in $\mathrm{mAb}$ therapy design [69].

These advantages will be examined further for each nanomaterial and how they can be modified and used to enhance the delivery or targeting of mAbs as a therapeutic option.

6.2. Mesoporous Silica Nanoparticles. Mesoporous silica nanoparticles (MSN) are relatively biocompatible, making them suitable for administration to patients [70,71], although they are not bioresorbable. These materials can be synthesized in a controlled manner allowing for the modification of pore shape and surface chemistry [72, 73], importantly allowing for the attachment of different $\mathrm{mAb}$ structures. Ultralarge pores have been produced [74], and this allows high capacity loading of mAbs.

Functionalized MSN has been loaded with a mAb raised to CTLA 4, 8, a protein elevated on the surface of tumor cells, and administered to mice with melanoma [31]. The administration of these particles showed an increased inhibition of tumor growth compared to the systemic administration of $\mathrm{mAb}$ alone. These results demonstrated that loading $\mathrm{mAb}$ into MSN did not alter the mAb effector functions, and by facilitating sustained antibody release, the half-life of the $\mathrm{mAb}$ was prolonged at the tumor site. 
MSN loaded with a mesothelin specific antibody was administered to mice with malignant mesotheliomas [32]. In this study, the particles were loaded with the cytotoxic drug, doxorubicin (DOX). The mesothelin specific antibody successfully targeted the MSN to tumor sites after intraperitoneal injection. It was observed that the targeted MSN were more effective than DOX alone and were able to help reduce the side effects of DOX treatment. Sundarraj et al. [33] have also conjugated epidermal growth factor receptor antibody to MSN to target lung cancer cells. Their system then released the cytotoxic drug, pyrrolidone-2, showing a 38\% enhancement in tumor inhibition. The system also showed low systemic toxicity.

MSN have been capped with gatekeepers, including chitosan-PEG copolymers, to regulate payload release, with this controlled by environmental changes at the site of pathology $[75,76]$. Deng et al. [64] have used $\mathrm{pH}$ sensitive chitosan in combination with hollow silica nanospheres to deliver protein payloads. The targeting antibody, ErbB2, was conjugated to the outer regions of the chitosan coating, allowing targeting to breast cancer cells. When administered to mice, there was elevated payload release in tumors $($ at $\mathrm{pH} 4$ ) when compared to normal tissue (at pH 7.4). This system may be useful for the delivery of mAbs not just to tumors but also to other sites of pathology where $\mathrm{pH}$ change may indicate a worsening pathology, including chronic wounds.

6.3. Porous Silicon. Porous silicon ( $\mathrm{pSi}$ ) is a high surface area $\left(800 \mathrm{~m}^{2} \mathrm{~g}^{-1}\right.$ [77]) biomaterial produced via the electrochemical etching of crystalline silicon wafers in hydrofluoric acid electrolyte solutions [77]. The pore size can be varied from $5 \mathrm{~nm}$ to $1-2 \mu \mathrm{m}$ based on the careful selection of fabrication parameters [77]. pSi can also be manufactured in many different morphologies such as films, membranes, microparticles, and nanoparticles [78] and is easily functionalized with readily available chemistries [79-83].

Andrew et al. [36] have demonstrated the loading of therapeutic $\mathrm{mAb}$ into $\mathrm{pSi}$. In this study, $800^{\circ} \mathrm{C}$ oxidized pSi films were effectively loaded with a high concentration of Bevacizumab, a mAb raised against vascular endothelial growth factor A. The controlled release of $94 \%$ of the payload was demonstrated over a 30-day period, with no initial burst release observed. Importantly, the released $\mathrm{mAb}$ retained its functionality as demonstrated by ELISA. Further studies are required to demonstrate the efficacy of these $\mathrm{mAb}$-loaded particles in vivo.

Another study has demonstrated the attachment of antibodies to $\mathrm{pSi}$, providing a targeting mechanism to deliver the cytotoxic agent, camptothecin [37]. Here, antibodies raised against cell-specific surface receptors were covalently grafted to the surface of pSi nanoparticles, allowing different cancer cell lines to be selectively targeted, namely, neuroblastoma (MLR2), glioblastoma (mAb528), and B lymphoma (Rituximab). The antibody-functionalized $\mathrm{pSi}$ nanoparticles selectively killed cells expressing the target receptor, therefore providing a promising therapeutic application. In another study, $\mathrm{Gu}$ et al. combined luminescent pSi nanoparticles with the FGK45 antibody, which activates B cells. They demonstrated that when this agonistic antibody was attached to the pSi nanoparticles, the activation of B cells was $40 \%$ higher compared to just free FGK45 antibody [38]. This is the first time an effect like this has been observed and could lead to a decrease in dosages required. The clever use of luminescent $\mathrm{pSi}$ nanoparticles by the authors also allows the nanoparticles to be readily tracked.

6.4. Gold Nanoparticles. There are a number of gold nanoparticle systems, including nanorods [41, 42], multifunctional nanoparticles containing a gold nanoshell [43], and traditional spherical nanoparticles $[39,40]$, that have been loaded with therapeutic mAbs. Developed to target rheumatoid arthritis and various cancers, these mAb-loaded particles show high specificity to the target cells [43] with low toxicity and retain antibody functionality [40]. Gold nanoparticles loaded with Tocilizumab ( $\alpha$-IL-6) have been used to treat an inducible rheumatoid arthritis mouse model, showing lowered IL-6 levels and a significant reduction in disease severity score [43]. In another study, gold nanorods loaded with a $\mathrm{mAb}$ that targets bladder cancer cells were administered via a urine catheter, followed by exposure to infrared light [42]. This treatment showed rapid clearance of bladder cancer cells. mAb-loaded gold nanorods have also been radiolabelled, enabling optical and nuclear imaging of the target tissue [41]. One major advantage of gold nanoparticles is the ability to use hyperthermia to destroy the target cells [40]. This involves the application of a continuous-wave near infrared laser and is especially useful in tumor treatment. This technique has fewer side effects than the use of cytotoxic drugs, which can kill cells nonspecifically and are retained in the patient until being metabolised.

6.5. Carbon-Based Nanomaterials. Carbon-based materials, such as nanographene, have modifiable surface chemistries, can be produced with ultra-high surface areas for drug loading, and also have unique electrical and optical properties. In one study, nanographene particles were bound to the $\mathrm{mAb}$, TRC105, which binds to CD105, a vascular marker for tumor angiogenesis [44]. When administered to a mouse model of cancer, there was effective nanoparticle targeting to the tumor. One major advantage of these particles is the capacity to use noninvasive positron emission tomography (PET) imaging to visualize the in vivo localisation of the nanographene. Similar to gold nanomaterials, photothermal therapy can also be used with nanographene particles, providing a therapeutic option for tumors.

Carbon nanotubes (CNTs) can be modified with a variety of surface chemistries, are soluble, biocompatible and allow protein binding $[84,85]$. Importantly, a number of research groups have demonstrated the ability of CNTs to traffic bound protein across cell membranes $[65,86]$. For example, Kam and Dai [65] have absorbed cytochrome C, streptavidin, protein A, and BSA to the walls of single walled CNTs that had been acid oxidized. They showed generic uptake into 4 cell lines, HeLa, NIH-3T3, HL60, and Jurkat cells. This was the first work to demonstrate the in vitro biological function of proteins delivered to the cytosol via CNTs. This property 
may be exploited for the delivery of therapeutic mAbs to intracellular locations.

6.6. Magnetic Nanoparticles. Superparamagnetic iron oxide nanoparticles (SPIONs) are a type of magnetic nanoparticle that can be functionalized, has near neutral zeta-potential, is large enough to avoid renal clearance, and is stable [45]. In one study, SPIONs were conjugated to an antibody raised against neu, a protein overexpressed in metastatic breast cancer. In mice, the SPIONs showed preferential association with mammary carcinoma cells. Superparamagnetism is important property of metal oxide nanoparticles as it allows the targeting of SPIONs to be visualized by MRI contrast agents [87]. This was observed when the neu-targeted SPIONs were administered to mice, showing enhanced MRI detection of small metastases. The ability to monitor, treat, and potentially diagnose metastatic breast cancer with the one system has the potential of providing an enormous benefit to cancer patients.

\section{Conclusion}

Inorganic nanoparticles present an exciting opportunity for both therapeutic mAb delivery and the use of mAbs to target drugs payloads. For the delivery of therapeutic $\mathrm{mAb}$, porous nanomaterials, such as $\mathrm{pSi}$ and MSN, have the capacity to hold large payloads, whilst providing a sustained release specifically tuned for optimal clinical efficacy. These particles provide the $\mathrm{mAb}$ protection from degradation, renal clearance, and retention in circulation by convection. The slow release of the $\mathrm{mAb}$ enables a reduction in the frequency of administration, which will reduce the cost of therapy and minimise side effects. There is also a strong likelihood that the binding side barrier effect will be decreased. For the use of $\mathrm{mAbs}$ as a targeting tool, inorganic nanoparticles provide protection for the payload, allow a large variety of compounds to be loaded, enable the option of photothermal ablation, and can be used as gatekeepers to control payload release.

$\mathrm{mAbs}$ can be effectively loaded into a variety of inorganic particles, retaining their functionality, with minimal side effects. These particles have been successfully targeted to the site of different pathologies. Importantly, clinical efficacy has been demonstrated in a number of mouse models of disease, including the treatment of tumors. These nanoparticles provide a host of other beneficial features, including the ability of some to naturally target tumors, cell penetrating properties, the use of PET to visualize the particles noninvasively, and their ability to target cells for death using photothermal ablation.

The ability to now combine many of these materials together into one device or delivery system and impart dual functionality is leading to the development of theranostic systems (including diagnosis, treatment, and monitoring of the disease). One could eventually imagine mAb-loaded particles floating through the blood stream or lying in wait until a disease state is detected, giving the body a potential immediate response, before the disease progresses beyond its initial phase. The continued development of these smart systems will eventually lead to more clinically beneficial and cost effective therapies for a wide range of diseases.

\section{Conflict of Interests}

The authors declare that there is no conflict of interests regarding the publication of this paper.

\section{Authors' Contribution}

Christopher T. Turner and Steven J. P. McInnes contributed equally to this work.

\section{Acknowledgment}

This research was conducted and funded by the Australian Research Council Centre of Excellence in Convergent Bio-Nano Science and Technology (project number CE140100036).

\section{References}

[1] J. Maynard and G. Georgiou, "Antibody engineering," Annual Review of Biomedical Engineering, vol. 2, no. 2000, pp. 339-376, 2000.

[2] P. Boross and J. H. Leusen, "Mechanisms of action of CD20 antibodies," American Journal of Cancer Research, vol. 2, no. 6, pp. 676-690, 2012.

[3] C. Chaudhury, S. Mehnaz, J. M. Robinson et al., "The major histocompatibility complex-related Fc receptor for IgG (FcRn) binds albumin and prolongs its lifespan," The Journal of Experimental Medicine, vol. 197, no. 3, pp. 315-322, 2003.

[4] A. L. Nelson, "Antibody fragments: hope and hype," $m A b s$, vol. 2, no. 1, pp. 77-83, 2010.

[5] Á. M. Cuesta, N. Sainz-Pastor, J. Bonet, B. Oliva, and L. ÁlvarezVallina, "Multivalent antibodies: when design surpasses evolution," Trends in Biotechnology, vol. 28, no. 7, pp. 355-362, 2010.

[6] U. Iyer and V. J. Kadambi, "Antibody drug conjugates-trojan horses in the war on cancer," Journal of Pharmacological and Toxicological Methods, vol. 64, no. 3, pp. 207-212, 2011.

[7] B. M. William and P. J. Bierman, "I-131 tositumomab," Expert Opinion on Biological Therapy, vol. 10, no. 8, pp. 1271-1278, 2010.

[8] J. E. Jackson, Z. Kopecki, D. H. Adams, and A. J. Cowin, "Flii neutralizing antibodies improve wound healing in porcine preclinical studies," Wound Repair and Regeneration, vol. 20, no. 4, pp. 523-536, 2012.

[9] A. Iannello and A. Ahmad, "Role of antibody-dependent cellmediated cytotoxicity in the efficacy of therapeutic anti-cancer monoclonal antibodies," Cancer and Metastasis Reviews, vol. 24, no. 4, pp. 487-499, 2005.

[10] Y. Zhuang, W. Xu, Y. Shen, and J. Li, "Fc $\gamma$ receptor polymorphisms and clinical efficacy of rituximab in non-hodgkin lymphoma and chronic lymphocytic leukemia," Clinical Lymphoma, Myeloma \& Leukemia, vol. 10, no. 5, pp. 347-352, 2010.

[11] L. G. Presta, "Engineering of therapeutic antibodies to minimize immunogenicity and optimize function," Advanced Drug Delivery Reviews, vol. 58, no. 5-6, pp. 640-656, 2006.

[12] X. Yang and A. Ambrogelly, "Enlarging the repertoire of therapeutic monoclonal antibodies platforms: domesticating half 
molecule exchange to produce stable IgG4 and IgG1 bispecific antibodies," Current Opinion in Biotechnology, vol. 30, pp. 225229, 2014

[13] A. Patel, K. Cholkar, and A. K. Mitra, "Recent developments in protein and peptide parenteral delivery approaches," Therapeutic Delivery, vol. 5, no. 3, pp. 337-365, 2014.

[14] G. Ismael, R. Hegg, S. Muehlbauer et al., "Subcutaneous versus intravenous administration of (neo)adjuvant trastuzumab in patients with HER2-positive, clinical stage I-III breast cancer (HannaH study): a phase 3, open-label, multicentre, randomised trial," The Lancet Oncology, vol. 13, no. 9, pp. 869-878, 2012.

[15] R. J. Keizer, A. D. R. Huitema, J. H. M. Schellens, and J. H. Beijnen, "Clinical pharmacokinetics of therapeutic monoclonal antibodies," Clinical Pharmacokinetics, vol. 49, no. 8, pp. 493507, 2010.

[16] Z. Kopecki, N. Ruzehaji, C. Turner et al., "Topically applied flightless i neutralizing antibodies improve healing of blistered skin in a murine model of epidermolysis bullosa acquisita," Journal of Investigative Dermatology, vol. 133, no. 4, pp. 10081016, 2013.

[17] P. Chames, M. van Regenmortel, E. Weiss, and D. Baty, "Therapeutic antibodies: successes, limitations and hopes for the future," British Journal of Pharmacology, vol. 157, no. 2, pp. 220 233, 2009.

[18] P. Vieira and K. Rajewsky, "The half-lives of serum immunoglobulins in adult mice," European Journal of Immunology, vol. 18, no. 2, pp. 313-316, 1988.

[19] D. C. Roopenian and S. Akilesh, "FcRn: the neonatal Fc receptor comes of age," Nature Reviews Immunology, vol. 7, no. 9, pp. 715725, 2007.

[20] S. Farajnia, V. Ahmadzadeh, A. Tanomand, K. Veisi, S. A. Khosroshahi, and L. Rahbarnia, "Development trends for generation of single-chain antibody fragments," Immunopharmacology and Immunotoxicology, vol. 36, no. 5, pp. 297-308, 2014.

[21] P. D. Senter, "Potent antibody drug conjugates for cancer therapy," Current Opinion in Chemical Biology, vol. 13, no. 3, pp. 235-244, 2009.

[22] K. Fujimori, D. G. Covell, J. E. Fletcher, and J. N. Weinstein, “A modeling analysis of monoclonal antibody percolation through tumors: a binding-site barrier," Journal of Nuclear Medicine, vol. 31, no. 7, pp. 1191-1198, 1990.

[23] G. P. Adams, R. Schier, A. M. McCall et al., "High affinity restricts the localization and tumor penetration of single-chain Fv antibody molecules," Cancer Research, vol. 61, no. 12, pp. 4750-4755, 2001

[24] R. Gniadecki, B. Bang, L. E. Bryld, L. Iversen, S. Lasthein, and L. Skov, "Comparison of long-term drug survival and safety of biologic agents in patients with psoriasis vulgaris," British Journal of Dermatology, 2014.

[25] G. Goldstein, J. Schindler, and H. Tsai, "A randomized clinical trial of OKT3 monoclonal antibody for acute rejection of cadaveric renal transplants," The New England Journal of Medicine, vol. 313, no. 6, pp. 337-342, 1985.

[26] F. M. Wagner, H. Reichenspurner, P. Uberfuhr et al., "How successful is OKT3 rescue therapy for steroid-resistant acute rejection episodes after heart transplantation?" The Journal of Heart and Lung Transplantation, vol. 13, no. 3, pp. 438-443, 1994.

[27] P. B. Jensen, S. A. Birkeland, N. Rohr, A. Elbirk, and K. A. Jørgensen, "Development of anti-OKT3 antibodies after OKT3 treatment," Scandinavian Journal of Urology and Nephrology, vol. 30, no. 3, pp. 227-230, 1996.

[28] L. Roque-Navarro, C. Mateo, J. Lombardero et al., "Humanization of predicted T-cell epitopes reduces the immunogenicity of chimeric antibodies: new evidence supporting a simple method," Hybridoma and Hybridomics, vol. 22, no. 4, pp. 245257, 2003.

[29] K.-S. Kim, H.-J. Kim, B. W. Han, P.-K. Myung, and H. J. Hong, "Construction of a humanized antibody to hepatitis B surface antigen by specificity-determining residues (SDR)-grafting and de-immunization," Biochemical and Biophysical Research Communications, vol. 396, no. 2, pp. 231-237, 2010.

[30] E. L. Sievers and P. D. Senter, "Antibody-drug conjugates in cancer therapy," Annual Review of Medicine, vol. 64, pp. 15-29, 2013.

[31] C. Lei, P. Liu, B. Chen et al., "Local release of highly loaded antibodies from functionalized nanoporous support for cancer immunotherapy," Journal of the American Chemical Society, vol. 132, no. 20, pp. 6906-6907, 2010.

[32] S. L. Macura, J. L. Steinbacher, M. B. MacPherson et al., "Microspheres targeted with a mesothelin antibody and loaded with doxorubicin reduce tumor volume of human mesotheliomas in xenografts," BMC Cancer, vol. 13, article 400, 2013.

[33] S. Sundarraj, R. Thangam, M. V. Sujitha, K. Vimala, and S. Kannan, "Ligand-conjugated mesoporous silica nanorattles based on enzyme targeted prodrug delivery system for effective lung cancer therapy," Toxicology and Applied Pharmacology, vol. 275, no. 3, pp. 232-243, 2014.

[34] F. Chen, H. Hong, Y. Zhang et al., "In vivo tumor targeting and image-guided drug delivery with antibody-conjugated, radiolabeled mesoporous silica nanoparticles," ACS Nano, vol. 7, no. 10, pp. 9027-9039, 2013.

[35] F. Chen, T. R. Nayak, S. Goel et al., "In vivo tumor vasculature targeted PET/NIRF imaging with TRC105(Fab)-conjugated, dual-labeled mesoporous silica nanoparticles," Molecular Pharmaceutics, vol. 11, no. 11, pp. 4007-4014, 2014.

[36] J. S. Andrew, E. J. Anglin, E. C. Wu et al., "Sustained release of a monoclonal antibody from electrochemically prepared mesoporous silicon oxide," Advanced Functional Materials, vol. 20, no. 23, pp. 4168-4174, 2010.

[37] E. Secret, K. Smith, V. Dubljevic et al., "Antibody-functionalized porous silicon nanoparticles for vectorization of hydrophobic drugs," Advanced Healthcare Materials, vol. 2, no. 5, pp. 718-727, 2013.

[38] L. Gu, L. E. Ruff, Z. Qin, M. Corr, S. M. Hedrick, and M. J. Sailor, "Multivalent porous silicon nanoparticles enhance the immune activation potency of agonistic CD40 antibody," Advanced Materials, vol. 24, no. 29, pp. 3981-3987, 2012.

[39] H. Lee, M.-Y. Lee, S. H. Bhang et al., "Hyaluronate-gold nanoparticle/Tocilizumab complex for the treatment of rheumatoid arthritis," ACS Nano, vol. 8, no. 5, pp. 4790-4798, 2014.

[40] G. Bisker, D. Yeheskely-Hayon, L. Minai, and D. Yelin, "Controlled release of Rituximab from gold nanoparticles for phototherapy of malignant cells," Journal of Controlled Release, vol. 162, no. 2, pp. 303-309, 2012.

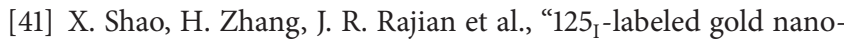
rods for targeted imaging of inflammation," ACS Nano, vol. 5, no. 11, pp. 8967-8973, 2011.

[42] S. K. Cho, K. Emoto, L.-J. Su, X. Yang, T. W. Flaig, and W. Park, "Functionalized gold nanorods for thermal ablation treatment of bladder cancer," Journal of Biomedical Nanotechnology, vol. 10, no. 7, pp. 1267-1276, 2014. 
[43] J. Shen, K. Li, L. Cheng, Z. Liu, S.-T. Lee, and J. Liu, "Specific detection and simultaneously localized photothermal treatment of cancer cells using layer-by-layer assembled multifunctional nanoparticles," ACS Applied Materials and Interfaces, vol. 6, no. 9, pp. 6443-6452, 2014.

[44] H. Hong, K. Yang, Y. Zhang et al., "In vivo targeting and imaging of tumor vasculature with radiolabeled, antibody-conjugated nanographene," ACS Nano, vol. 6, no. 3, pp. 2361-2370, 2012.

[45] F. M. Kievit, Z. R. Stephen, O. Veiseh et al., "Targeting of primary breast cancers and metastases in a transgenic mouse model using rationally designed multifunctional SPIONs," ACS Nano, vol. 6, no. 3, pp. 2591-2601, 2012.

[46] J. Kost and R. Langer, "Responsive polymeric delivery systems," Advanced Drug Delivery Reviews, vol. 46, no. 1-3, pp. 125-148, 2001.

[47] Y. Cao, B. Wang, Y. Wang, and D. Lou, "Dual drug release from core-shell nanoparticles with distinct release profiles," Journal of Pharmaceutical Sciences, vol. 103, no. 10, pp. 3205-3216, 2014.

[48] Y. Chang and L. Xiao, "Preparation and characterization of a novel drug delivery system: biodegradable nanoparticles in thermosensitive chitosan/gelatin blend hydrogels," Journal of Macromolecular Science Part A: Pure and Applied Chemistry, vol. 47, no. 6, pp. 608-615, 2010.

[49] Y. Hou, J. Hu, H. Park, and M. Lee, "Chitosan-based nanoparticles as a sustained protein release carrier for tissue engineering applications," Journal of Biomedical Materials Research-Part A, vol. 100, no. 4, pp. 939-947, 2012.

[50] V. E. Santo, A. R. C. Duarte, M. E. Gomes, J. F. Mano, and R. L. Reis, "Hybrid 3D structure of poly(d,l-lactic acid) loaded with chitosan/chondroitin sulfate nanoparticles to be used as carriers for biomacromolecules in tissue engineering," Journal of Supercritical Fluids, vol. 54, no. 3, pp. 320-327, 2010.

[51] H. Valo, S. Arola, P. Laaksonen et al., "Drug release from nanoparticles embedded in four different nanofibrillar cellulose aerogels," European Journal of Pharmaceutical Sciences, vol. 50, no. 1, pp. 69-77, 2013.

[52] F. Z. Volpato, J. Almodóvar, K. Erickson, K. C. Popat, C. Migliaresi, and M. J. Kipper, "Preservation of FGF-2 bioactivity using heparin-based nanoparticles, and their delivery from electrospun chitosan fibers," Acta Biomaterialia, vol. 8, no. 4, pp. 1551-1559, 2012.

[53] S. K. Yandrapu, A. K. Upadhyay, J. M. Petrash, and U. B. Kompella, "Nanoparticles in porous microparticles prepared by supercritical infusion and pressure quench technology for sustained delivery of bevacizumab," Molecular Pharmaceutics, vol. 10, no. 12, pp. 4676-4686, 2013.

[54] M. R. Green, G. M. Manikhas, S. Orlov et al., "Abraxane, a novel Cremophor-free, albumin-bound particle form of paclitaxel for the treatment of advanced non-small-cell lung cancer," Annals of Oncology, vol. 17, no. 8, pp. 1263-1268, 2006.

[55] E. Andreopoulou, D. Gaiotti, E. Kim et al., "Pegylated liposomal doxorubicin HCL (PLD; Caelyx/Doxil): experience with longterm maintenance in responding patients with recurrent epithelial ovarian cancer," Annals of Oncology, vol. 18, no. 4, pp. 716721, 2007.

[56] P. Yang, S. Gai, and J. Lin, "Functionalized mesoporous silica materials for controlled drug delivery," Chemical Society Reviews, vol. 41, no. 9, pp. 3679-3698, 2012.

[57] E. J. Anglin, L. Cheng, W. R. Freeman, and M. J. Sailor, "Porous silicon in drug delivery devices and materials," Advanced Drug Delivery Reviews, vol. 60, no. 11, pp. 1266-1277, 2008.
[58] S. J. P. McInnes and N. H. Voelcker, "Silicon-polymer hybrid materials for drug delivery," Future Medicinal Chemistry, vol. 1, no. 6, pp. 1051-1074, 2009.

[59] D. Fine, A. Grattoni, R. Goodall et al., "Silicon micro- and nanofabrication for medicine," Advanced Healthcare Materials, vol. 2, no. 5, pp. 632-666, 2013.

[60] A. M. A. Elhissi, W. Ahmed, I. U. Hassan, V. R. Dhanak, and A. D'Emanuele, "Carbon nanotubes in cancer therapy and drug delivery," Journal of Drug Delivery, vol. 2012, Article ID 837327, 10 pages, 2012.

[61] D. Kumar, N. Saini, N. Jain, R. Sareen, and V. Pandit, "Gold nanoparticles: an era in bionanotechnology," Expert Opinion on Drug Delivery, vol. 10, no. 3, pp. 397-409, 2013.

[62] S. Bose, S. Tarafder, J. Edgington, and A. Bandyopadhyay, "Calcium phosphate ceramics in drug delivery," JOM, vol. 63, no. 4, pp. 93-98, 2011.

[63] I. I. Slowing, B. G. Trewyn, and V. S.-Y. Lin, "Mesoporous silica nanoparticles for intracellular delivery of membraneimpermeable proteins," Journal of the American Chemical Society, vol. 129, no. 28, pp. 8845-8849, 2007.

[64] Z. Deng, Z. Zhen, X. Hu, S. Wu, Z. Xu, and P. K. Chu, "Hollow chitosan-silica nanospheres as $\mathrm{pH}$-sensitive targeted delivery carriers in breast cancer therapy," Biomaterials, vol. 32 , no. 21, pp. 4976-4986, 2011.

[65] N. W. S. Kam and H. Dai, "Carbon nanotubes as intracellular protein transporters: generality and biological functionality," Journal of the American Chemical Society, vol. 127, no. 16, pp. 6021-6026, 2005.

[66] P. M. Tiwari, E. Eroglu, S. S. Bawage et al., "Enhanced intracellular translocation and biodistribution of gold nanoparticles functionalized with a cell-penetrating peptide (VG-21) from vesicular stomatitis virus," Biomaterials, vol. 35 , no. 35 , pp. 9484-9494, 2014.

[67] H. Maeda, J. Wu, T. Sawa, Y. Matsumura, and K. Hori, “Tumor vascular permeability and the EPR effect in macromolecular therapeutics: a review," Journal of Controlled Release, vol. 65, no. 1-2, pp. 271-284, 2000.

[68] K. Greish, "Enhanced permeability and retention of macromolecular drugs in solid tumors: a royal gate for targeted anticancer nanomedicines," Journal of Drug Targeting, vol. 15, no. 7-8, pp. 457-464, 2007.

[69] R. H. Weisbart, J. F. Gera, G. Chan et al., "A cell-penetrating bispecific antibody for therapeutic regulation of intracellular targets," Molecular Cancer Therapeutics, vol. 11, no. 10, pp. 21692173, 2012.

[70] C.-Y. Lai, B. G. Trewyn, D. M. Jeftinija et al., "A mesoporous silica nanosphere-based carrier system with chemically removable CdS nanoparticle caps for stimuli-responsive controlled release of neurotransmitters and drug molecules," Journal of the American Chemical Society, vol. 125, no. 15, pp. 4451-4459, 2003.

[71] S. Radin, S. Falaize, M. H. Lee, and P. Ducheyne, "In vitro bioactivity and degradation behavior of silica xerogels intended as controlled release materials," Biomaterials, vol. 23, no. 15, pp. 3113-3122, 2002.

[72] C. T. Kresge, M. E. Leonowicz, W. J. Roth, J. C. Vartuli, and J. S. Beck, "Ordered mesoporous molecular sieves synthesized by a liquid-crystal template mechanism," Nature, vol. 359, no. 6397, pp. 710-712, 1992.

[73] M. Vallet-Regí, F. Balas, and D. Arcos, "Mesoporous materials for drug delivery," Angewandte Chemie, vol. 46, no. 40, pp. 7548-7558, 2007. 
[74] H.-S. Shin, Y.-K. Hwang, and S. Huh, "Facile preparation of ultra-large pore mesoporous silica nanoparticles and their application to the encapsulation of large guest molecules," ACS Applied Materials and Interfaces, vol. 6, no. 3, pp. 1740-1746, 2014.

[75] C. Park, H. Kim, S. Kim, and C. Kim, "Enzyme responsive nanocontainers with cyclodextrin gatekeepers and synergistic effects in release of guests," Journal of the American Chemical Society, vol. 131, no. 46, pp. 16614-16615, 2009.

[76] A. Pourjavadi and Z. M. Tehrani, "Mesoporous silica nanoparticles (MCM-41) coated PEGylated chitosan as a $\mathrm{pH}$-responsive nanocarrier for triggered release of erythromycin," International Journal of Polymeric Materials and Polymeric Biomaterials, vol. 63, no. 13, pp. 692-697, 2014.

[77] L. Canham, Properties of Porous Silicon, Short Run Press, London, UK, 2006.

[78] S. J. P. McInnes and N. H. Voelcker, "Porous silicon-polymer composites for cell culture and tissue engineering applications," in Porous Silicon for Biomedical Applications, Woodhead, Cambridge, UK, 2014.

[79] J. Schmeltzer and J. Buriak, Recent Developments in the Chemistry and Chemical Applications of Porous Silicon, Wiley-VCH, Weinheim, Germany, 2004.

[80] M. P. Stewart and J. M. Buriak, "Chemical and biological applications of porous silicon technology," Advanced Materials, vol. 12, no. 12, pp. 859-869, 2000.

[81] W. H. Green, S. Létant, and M. J. Sailor, "Electrochemical formation and modification of nanocrystalline porous silicon," in Electrochemistry of Nanomaterials, G. Hodes, Ed., pp. 141-167, Wiley, 2001.

[82] M. P. Stewart and J. M. Buriak, "New approaches toward the formation of silicon-carbon bonds on porous silicon," Comments on Inorganic Chemistry, vol. 23, no. 3, pp. 179-203, 2002.

[83] J. Salonen and V.-P. Lehto, "Fabrication and chemical surface modification of mesoporous silicon for biomedical applications," Chemical Engineering Journal, vol. 137, no. 1, pp. 162-172, 2008.

[84] S. Jain, S. R. Singh, and S. Pillai, "Toxicity issues related to biomedical applications of carbon nanotubes," Journal of Nanomedicine \& Nanotechnology, vol. 3, no. 5, 2012.

[85] C. Salvador-Morales, E. Flahaut, E. Sim, J. Sloan, M. L. H. Green, and R. B. Sim, "Complement activation and protein adsorption by carbon nanotubes," Molecular Immunology, vol. 43, no. 3, pp. 193-201, 2006.

[86] N. W. S. Kam, T. C. Jessop, P. A. Wender, and H. Dai, "Nanotube molecular transporters: internalization of carbon nanotube-protein conjugates into mammalian cells," Journal of the American Chemical Society, vol. 126, no. 22, pp. 6850-6851, 2004.

[87] L. Josephson, "Magnetic nanoparticles for MR imaging," in BioMEMS and Biomedical Nanotechnology, M. Ferrari, Ed., pp. 227-237, Springer, Boston, Mass, USA, 2006. 

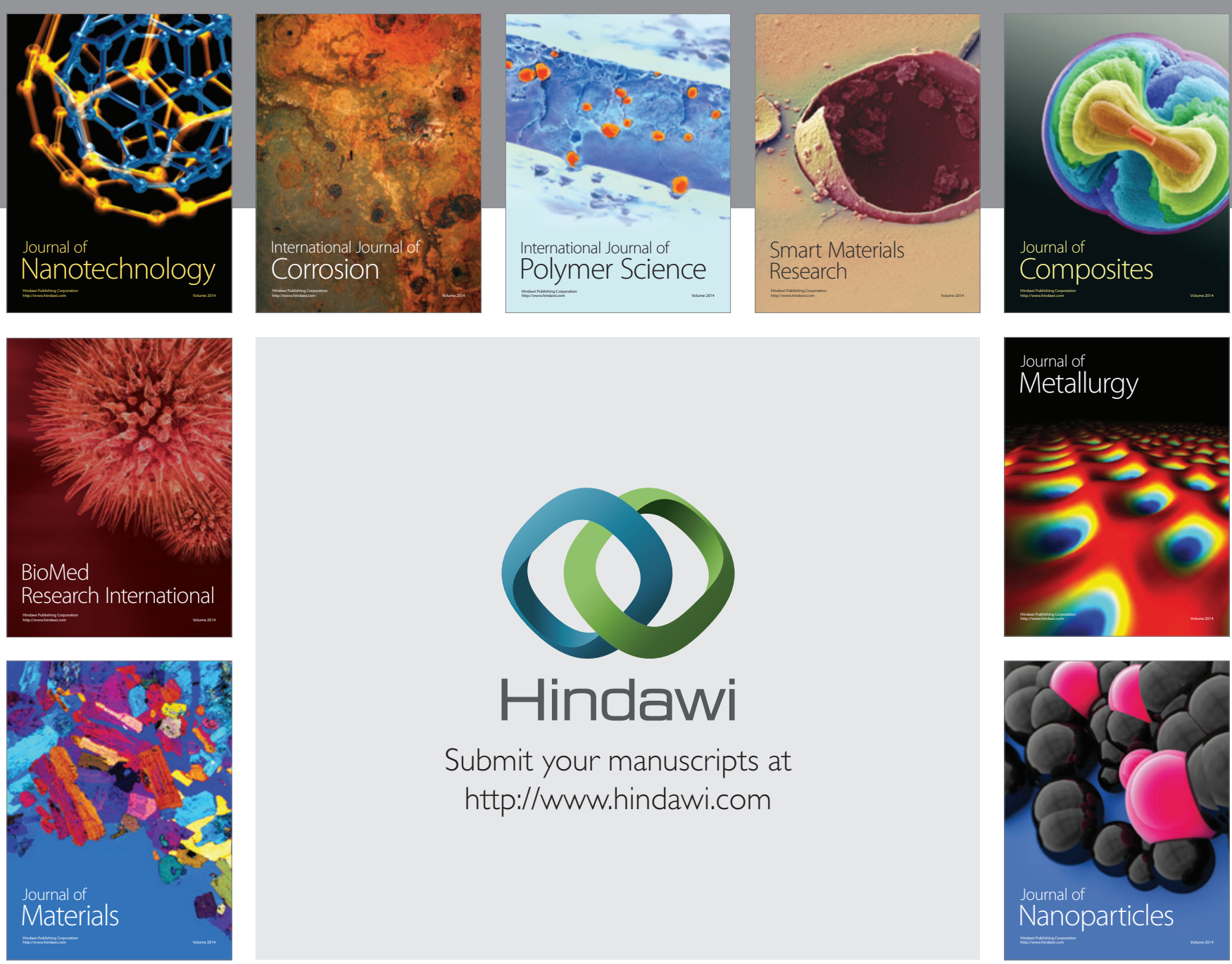

Submit your manuscripts at http://www.hindawi.com
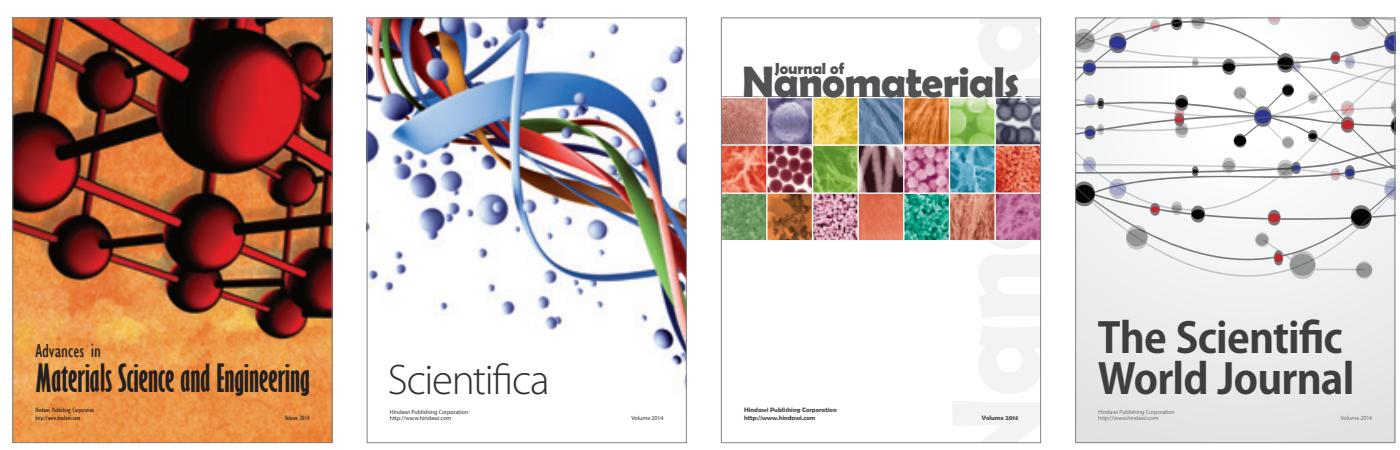

\section{The Scientific World Journal}
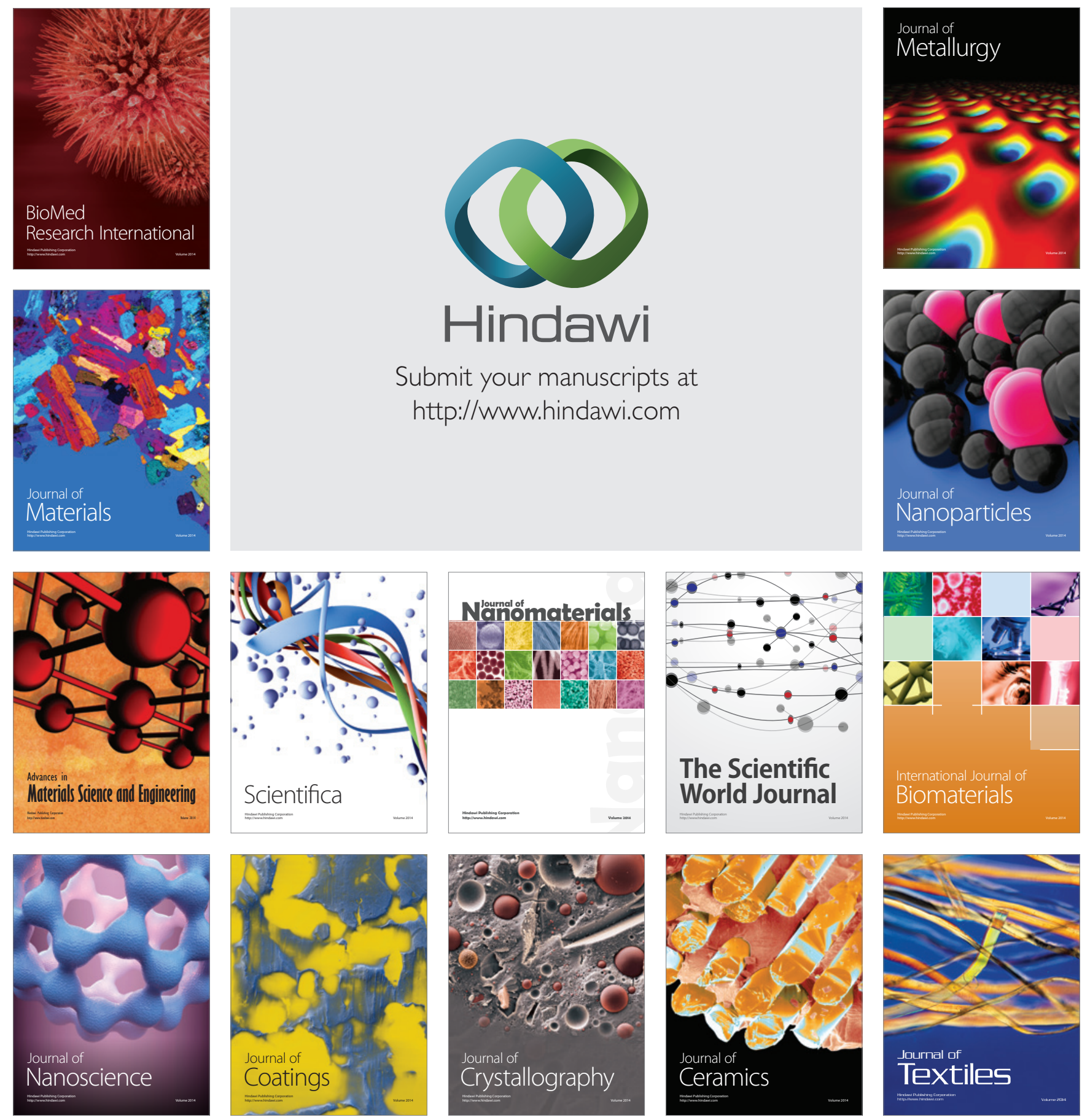